\title{
Model Epidemik SIR Penyebaran Penyakit Tuberkulosis dengan Vaksinasi
}

\author{
Indrawati Lihawa1, Fikran Datau' ${ }^{2}$, Patria Akuba ${ }^{3}$, Ismail Anani ${ }^{4}$ \\ 1,2,3,4 Jurusan Matematika, Fakultas MIPA, Universitas Negeri Gorontalo, \\ Jl. Prof. Dr. Ing. B. J. Habibie, Tilongkabila, Kabupaten Bone Bolango, Gorontalo 96119, Indonesia
}

Email Korespondensi:indrawatylihawa06@gmail.com

\begin{abstract}
ABSTRAK
Penyakit Tuberkulosis adalah penyakit menular disebabkan oleh bakteri Mycobacterium Tuberculosis. Penelitian ini membahas analisis model yang dilakukan dengan penentuan titik tetap tanpa penyakit dan titik tetap dengan penyakit, dan dilakukan analisis kestabilan pada titik tetap. Hasil analisis yang diperoleh menunjukkan bahwa parameter yang paling berpengaruh terhadap titik endemik kelas infeksi adalah banyaknya kelahiran populasi dan besarnya vaksinasi yang diberikan, artinya untuk dapat mengurangi jumlah individu terinfeksi dalam populasi maka banyaknya kelahiran harus kecil dan tingkat keberhasilan vaksinasi harus semakin besar, dengan kata lain perlu intervensi yang dilakukan untuk mengurangi banyaknya kelahiran individu dan kekuatan vaksin yang diberikan pada bayi. Selanjutnya diikuti laju kematian akibat Tuberculosis, diikuti laju kematian alami, diikuti laju penularan penyakit Tuberkulosis, dan diikuti laju individu sembuh setelah terinfeksi Tuberkulosis.

Kata Kunci:

Tuberkulosis; Vaksinasi; Model Epidemik; SIR
\end{abstract}

\section{Pendahuluan}

Tuberkulosis merupakan penyakit yang menyerang paru-paru dan disebabkan oleh bakteri Mycobacterium tuberculosis. Penyakit ini bisa menyebar pada bagian tubuh lain yaitu selaput yang melindungi sistem saraf pusat, ginjal, tulang, dan kelenjar getah bening [1]. Penyakit Tuberkulosis adaah penyebab kematian nomor 3 setelah penyakit jantung dan penyakit saluran pernafasan pada semua usia, dan urutan pertama pada golongan penyakit infeksi [2]. Vaksin Bacillus Calmette-Guérin adalah vaksin hidup yang di lemahkan berasal dari bakteri Mycobacterium bovis dan dirancang untuk menimbulkan reaksi kekebalan terhadap bakteri Mycobacterium tuberculosis. Pada awalnya, Bacillus Calmette Guerin adalah temuan Albert Calmette dan Camille Guérin di Prancis berasal dari basil tuberkel M. bovis sesuai nama penyakit [3].

Model dasar tentang penyebaran penyakit epidemi pertama kali dirumuskan oleh Kermack dan McKendrick tahun 1927. Dalam modelnya, Kermack dan McKendrick membagi populasi menjadi tiga bagian, yaitu Susceptible (S) yaitu jumlah individu sehat tapi rentan terhadap penyakit, Infected (I) yaitu jumlah individu terinfeksi dan bisa menularkan penyakit pada individu sehat, dan Recovered $(R)$ yang menotasikan jumlah individu yang sembuh dari penyakit dan akan kebal dari penyakit [4]. Pada model lain dibahas mengenai analisis sensitivitas penyebaran penyakit Tuberculosis [5]. Dari model tersebut dilakukan analisis sensitivitas dengan mencari indeks sensitivitas setiap 
parameter terhadap bilangan reproduksi dasar, titik endemik kelas infected, sampai mensimulasikan menggunakan Aplikasi Maple [6].

Pada artikel ini diperkenalkan model baru dengan mempertimbangkan model matematika epidemik penyebaran penyakit Tubercolosis dengan pemberian Vaksin BCG. Vaksin dikembangkan dari bakteri Mycobacterium bovis, bakteri yang menjadi penyebab Tuberkulosis pada sapi dan monyet. Tapi, karakteristik dari bakteri M. bovis ini seperti bakteri Tuberkulosis pada manusia, yakni Mycobacterium tuberculosis [7]. Pada model ini digunakan beberapa variabel yaitu variabel $B$ yang merepresentasikan kelompok individu bayi yang sehat, yaitu individu yang ada kemungkinan rentan terkena penyakit Tuberculosis apabila tidak diberi vaksin. Variabel $S$ yang merepresentasikan kelompok individu yang rentan terkena penyakit Tuberculosis. I kelompok invidu yang terinfeksi oleh penyakit Tuberculosis. $R$ kelompok individu yang sudah sembuh dari penyakit dan tidak akan mungkin kembali terinfeksi penyakit.

Tujuan penelitian ini untuk mengamati apakah vaksinasi pada bayi bisa mempengaruhi penyebaran penyakit Tuberkulosis. Dengan melihat keadaan individu rentan, terinfeksi, dan sembuh apakah naik, turun, dan stabil pada interval waktu tertentu.

\section{Metode}

Pada penelitian di lakukan menggunakan metode studi literatur. Ini dilakukan untuk mencermati, mendalami, menelaah,serta mengidentifikasi pengetahuan untuk menunjang penelitian. Sumber yang digunakan berupa buku, jurnal, skripsi, tesis, atau internet. Langkah-langkah pembentukan model matematika penyebaran penyakit TBC yaitu: (1) Mengidentifikasi Masalah, dengan membaca serta memahami literatur berkaitan dengan penyakit TBC dan pemodelan matematika, sehingga dapat ditentukan sub-sub populasi yang di gunakan pada model; (2) Membuat Asumsi, dengan pembuatan model matematika tidak semua faktor berpengaruh pada penyebaran penyakit TBC bisa dimodelkan secara matematik, maka perlu di sederhanakan dengan cara melakukan reduksi faktorfaktor berpengaruh peristiwa ini; (3) Menginterpretasikan dan Menyelesaikan Model, perlu diselesaikan dengan cara matematika yaitu melakukan analisis parameter dan mencari titik kritis, nilai eigen, dan basik reproduksi rasio (R0); (4) Verifikasi Model, setelah melakukan analisis pada model, perlu simulasi model. Simulasi untuk menguji hasil analisis dengan melihat pengaruh parameter.

\section{Hasil dan Pembahasan}

\subsection{Model Matematika}

Dalam penelitian ini, model yang akan dibahas adalah model matematika epidemik penyebaran penyakit TBC dengan memberikan Vaksin. Dalam model ini digunakan beberapa variabel yaitu B kelompok individu bayi yang sehat, yaitu individu yang kemungkinan rentan terkena penyakit TBC apabila tidak diberikan vaksin. $\mathbf{S}$ kelompok individu yang rentan terkena penyakit TBC. I kelompok invdividu yang terinfeksi oleh penyakit TBC. $\mathbf{R}$ kelompok individu yang telah sembuh dari penyakit dan tidak akan mungkin terinfeksi kembali.

\section{Asumsi-asumsi yang digunakan:}

a. Pertumbuhan populasi konstan 
b. Laju kelahiran individu sama dengan laju kematiannya

c. Perubahan individu $S$ dan $I$ proposional pada jumlah populasi

d. Individu terinfeksi di asumsikan bisa kembali sembuh dengan peluang konstan sepanjang waktu

e. Individu terinfeksi ada kemungkinan meninggal karena penyakit Tuberculosis

f. Individu terinfeksi dan kemudian sembuh, maka individu tersebut tidak akan terinfeksi kembali karena adanya kekebalan tubuh yang kuat

g. Individu yang telah di beri vaksin tidak akan terinfeksi oleh virus

h. Kemampuan vaksin adalah $100 \%$. Hal ini berarti setiap individu yang telah di vaksin akan kebal dari penyakit dan tidak bisa terjangkit kembali

i. Vaksin hanya diberikan kepada individu yang baru lahir yaitu antara usia 1 sampai 2 bulan

\section{Variabel yang digunakan}

- $\mathbf{B}=$ Populasi bayi

- $\mathbf{S}$ = Individu rentan

- I = Individu terinfeksi

- $\mathbf{R}$ = Individu sembuh

\section{Parameter yang digunakan}

- $\mu$ = Laju kelahiran

- $\beta=$ Laju individu terinfeksi

- $\delta$ = Laju individu sembuh

- $a$ = Peluang vaksinasi

- $\rho=$ Laju kematian secara alami

- $\lambda$ = Laju kematian karena penyakit

Dengan adanya asumsi, variabel dan parameter di atas, maka diagram kompartemen untuk penyebaran penyakit $T B C$ dengan vaksinasi dapat dilihat pada Gambar 1 .

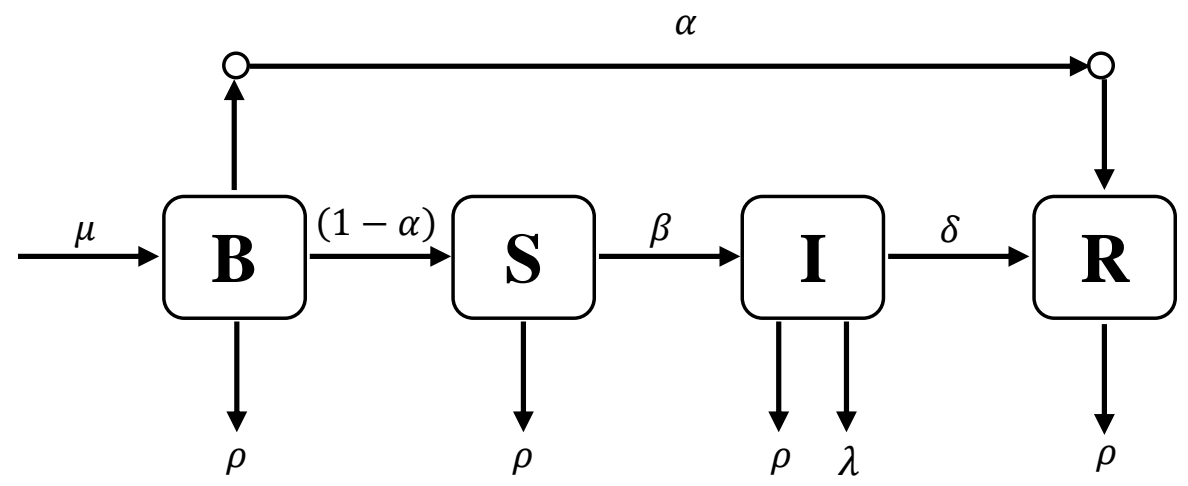

Gambar 1. Diagram kompartmen penyebaran TBC 
Sehingga model matematika dari diagram tersebut di uraikan sebagai berikut:

$$
\begin{aligned}
& \frac{d B}{d t}=\mu-\alpha B-\rho B-(1-\alpha) B \\
& \frac{d S}{d t}=(1-\alpha) B-\rho s-\beta S I \\
& \frac{d I}{d t}=\beta S I-\rho I-\lambda I-\delta I \\
& \frac{d R}{d t}=\alpha B+\delta I-\rho R
\end{aligned}
$$

\subsection{Analisis Model}

\subsubsection{Penentuan Titik Tetap}

Titik tetap model penyebaran penyakit Tuberkulosis dengan vaksinasi diperoleh dengan menetapkan persamaan-persamaan pada sistem menjadi konstan terhadap waktu atau $\frac{d B}{d t}=0, \frac{d S}{d t}=0, \frac{d I}{d t}=0$, dan $\frac{d R}{d t}=0$ sehingga sistem persamaan dapat ditulis sebagai :

\section{Titik Tetap Tanpa Penyakit}

$$
\begin{array}{r}
\mu-[\alpha+\rho+(1-\alpha)] \mathrm{B}=0 \\
(1-\alpha) B-\rho S-\beta S I=0 \\
\beta S I-\rho I-\lambda I-\delta I=0 \\
\alpha B+\delta I-\rho R=0
\end{array}
$$

Titik tetap tanpa penyakit dapat dinyatakan dengan bentuk $E_{0}=(\mathrm{B}, S, I, R)$ terjadi jika $I=0$

- Untuk nilai $B$ diperoleh sebagai berikut:

$$
\begin{aligned}
\frac{d B}{d t}=0, \text { maka diperoleh: } & \\
\mu-[\alpha+\rho+(1-\alpha)] \mathrm{B} & =0 \\
-[\alpha+\rho+(1-\alpha)] \mathrm{B} & =-\mu \\
{[\alpha+\rho+(1-\alpha)] \mathrm{B} } & =\mu \\
\mathrm{B} & =\frac{\mu}{[\alpha+\rho+(1-\alpha)]}
\end{aligned}
$$

- Untuk nilai $S$ diperoleh sebagai berikut:

$$
\frac{d s}{d t}=0, \text { maka diperoleh: }
$$

$$
\begin{gathered}
(1-\alpha) B-\rho S-\beta S I=0 \\
(1-\alpha) B-\rho S=0 \\
-\rho S=-(1-\alpha) B \\
\rho S=(1-\alpha) B \\
S=\frac{(1-\alpha) B}{\rho}
\end{gathered}
$$

Subtitusi nilai B ke dalam persamaan di atas: 


$$
\begin{aligned}
& S=\frac{(1-\alpha) \frac{\mu}{[\alpha+\rho+(1-\alpha)]}}{\rho} \\
& S=\frac{(1-\alpha) \mu}{[\alpha+\rho+(1-\alpha)] \rho}
\end{aligned}
$$

- Untuk nilai $R$ diperoleh sebagai berikut:

$$
\begin{aligned}
& \frac{d R}{d t}=0, \text { maka diperoleh: } \\
& \qquad \begin{aligned}
\alpha B+\delta I-\rho R & =0 \\
\alpha B-\rho R & =0 \\
-\rho R & =-\alpha B \\
\rho R & =\alpha B \\
R & =\frac{\alpha B}{\rho}
\end{aligned}
\end{aligned}
$$

Subtitusi nilai B kedalam persamaan di atas:

Jadi titik tetap tanpa penyakit adalah

$$
\begin{aligned}
R & =\frac{\alpha\left(\frac{\mu}{[\alpha+\rho+(1-\alpha)]}\right)}{\rho} \\
R & =\frac{\alpha \mu}{[\alpha+\rho+(1-\alpha)] \rho}
\end{aligned}
$$

$$
E_{0}=\left(\frac{\mu}{[\alpha+\rho+(1-\alpha)]}, \frac{(1-\alpha) \mu}{[\alpha+\rho+(1-\alpha)] \rho}, 0, \frac{\alpha \mu}{[\alpha+\rho+(1-\alpha)] \rho}\right)
$$

\section{Titik Tetap Dengan Penyakit}

Titik tetap dengan penyakit dapat dinyatakan dalam bentuk $E_{1}=(S, I, R)$ berdasarkan pada sistem persamaan pada model tersebut diperoleh:

- Untuk $\frac{d I}{d t}=0$, diperoleh:

$$
\begin{aligned}
\beta S I-\rho I-\lambda I-\delta I=0 & \\
(\beta S-\rho-\lambda-\delta) I & =0 \\
I=0 \vee \quad(\beta S-\rho-\lambda-\delta) & =0 \\
(\beta S-\rho-\lambda-\delta) & =0 \\
\beta S & =\rho+\lambda+\delta \\
S & =\frac{\rho+\lambda+\delta}{\beta}
\end{aligned}
$$

- Untuk $\frac{d B}{d t}=0$, diperoleh:

$$
\begin{aligned}
\mu-[\alpha+\rho+(1-\alpha)] B & =0 \\
-[\alpha+\rho+(1-\alpha)] B & =\mu \\
B & =\frac{\mu}{[\alpha+\rho+(1-\alpha)]}
\end{aligned}
$$

- Untuk $\frac{d S}{d t}=0$, diperoleh:

$$
\begin{aligned}
& (1-\alpha) B-\rho S-\beta S I=0 \\
& (1-\alpha) B-(\rho-\beta I) S=0
\end{aligned}
$$




$$
\begin{aligned}
-(\rho-\beta I) S & =-(1-\alpha) B \\
(\rho-\beta I) S & =(1-\alpha) B \\
S & =\frac{(1-\alpha) B}{\rho-\beta I}
\end{aligned}
$$

Subtitusi persamaan (1) ke persamaan (3)

$$
\begin{aligned}
\frac{(1-\alpha) B}{\rho-\beta I} & =\frac{\rho+\lambda+\delta}{\beta} \\
(\rho+\lambda+\delta)(\rho-\beta I) & =\beta \cdot(1-\alpha) B \\
\rho-\beta I & =\frac{\beta \cdot(1-\alpha) B}{\rho+\lambda+\delta} \\
-\beta I & =\frac{\beta \cdot(1-\alpha) B}{\rho+\lambda+\delta}-\rho
\end{aligned}
$$

Kalikan kedua ruas dengan $-\frac{1}{\beta^{\prime}}$, maka diperoleh:

$$
I=\rho-\frac{(1-\alpha) B}{\rho+\lambda+\delta}
$$

Subtitusi persamaan (2) ke persamaan (4)

$$
\begin{aligned}
& I=\rho-\frac{(1-\alpha) \frac{\mu}{\alpha+\rho+(1-\alpha)}}{\rho+\lambda+\delta} \\
& I=\rho-\frac{(1-\alpha)}{[\alpha+\rho+(1-\alpha)] \cdot(\rho+\lambda+\delta)}
\end{aligned}
$$

- Untuk $\frac{d R}{d t}=0$, diperoleh:

$$
\begin{gathered}
\alpha B+\delta I-\rho R=0 \\
-\rho R=-\alpha B-\delta I \\
\rho R=\alpha B+\delta I \\
R=\frac{\alpha B+\delta I}{\rho}
\end{gathered}
$$

Subtitusi persamaan (2) ke persamaan (6)

$$
\begin{aligned}
R & =\frac{\alpha\left(\frac{\mu}{\alpha+\rho+(1-\alpha)}\right)+\delta I}{\rho} \\
R & =\frac{\alpha \mu}{[\alpha+\rho+(1-\alpha)] \rho}+\frac{\delta I}{\rho}
\end{aligned}
$$

Subtitusi persamaan (5) ke persamaan (7)

$$
\begin{aligned}
& R=\frac{\alpha \mu}{[\alpha+\rho+(1-\alpha)] \rho}+\frac{\delta I}{\rho} \\
& R=\frac{\alpha \mu}{[\alpha+\rho+(1-\alpha)] \rho}+\frac{\delta\left(\rho-\frac{(1-\alpha)}{[\alpha+\rho+(1-\alpha)] \cdot(\rho+\lambda+\delta)}\right)}{\rho} \\
& R=\frac{\alpha \mu}{[\alpha+\rho+(1-\alpha)] \rho}+\left(\delta-\frac{\delta(1-\alpha)}{\rho[\alpha+\rho+(1-\alpha)] \cdot(\rho+\lambda+\delta)}\right)
\end{aligned}
$$

Jadi titik tetap dengan penyakit adalah: 


$$
\begin{gathered}
E_{1}=\left(\frac{\mu}{[\alpha+\rho+(1-\alpha)]}, \frac{\rho+\lambda+\delta}{\beta}, \rho-\frac{(1-\alpha)}{[\alpha+\rho+(1-\alpha)] \cdot(\rho+\lambda+\delta)}, \frac{\alpha \mu}{[\alpha+\rho+(1-\alpha)] \rho}\right. \\
\left.\quad+\frac{\delta\left(\rho-\frac{(1-\alpha)}{[\alpha+\rho+(1-\alpha)] \cdot(\rho+\lambda+\delta)}\right)}{\rho}\right) \\
E_{1}=\left(\frac{\mu}{[\alpha+\rho+(1-\alpha)]}, \frac{\rho+\lambda+\delta}{\beta}, \rho-\frac{(1-\alpha)}{[\alpha+\rho+(1-\alpha)] \cdot(\rho+\lambda+\delta)}, \frac{\alpha \mu}{[\alpha+\rho+(1-\alpha)] \rho}\right. \\
\left.\quad+\left(\delta-\frac{\delta(1-\alpha)}{\rho[\alpha+\rho+(1-\alpha)] \cdot(\rho+\lambda+\delta)}\right)\right)
\end{gathered}
$$

\subsubsection{Menentukan Bilangan Reproduksi Dasar $\left(\boldsymbol{R}_{\mathbf{0}}\right)$}

Bilangan reproduksi yang dinotasikan dengan $\mathrm{R}_{0}$ adalah nilai harapan banyaknya infeksi tiap satuan waktu [8][9]. Infeksi ini terjadi pada suatu populasi rentan yang dihasilkan oleh satu individu terinfeksi. Selanjutnya, bilangan reproduksi dasar ditentukan dengan menggunakan pendekatan next gereration matrix [8][9][10]. Berdasarkan sistem persamaan (1), diambil sistem persamaan yang memuat populasi terpapar dan terinfeksi, yaitu

$$
\begin{aligned}
\frac{d B}{d t} & =\mu-[\alpha+\rho+(1-\alpha)] \mathrm{B} \\
\frac{d S}{d t} & =(1-\alpha) B-\rho S-\beta S I \\
\frac{d I}{d t} & =\beta S I-\rho I-\lambda I-\delta I \\
\frac{d R}{d t} & =\alpha B+\delta I-\rho R
\end{aligned}
$$

Berdasarkan sistem persamaan di atas, diperoleh matriks $\mathrm{F}$ dan $\mathrm{V}$ sebagai berikut

- Matriks F

$$
\left[\begin{array}{c}
\rho S I \\
\alpha B+\delta I
\end{array}\right]
$$

- Matriks V

$$
\left[\begin{array}{c}
(\rho+\lambda+\delta) I \\
\rho R
\end{array}\right]
$$

Matriks Jacobian dari matriks $F$ dan $V$ di atas dinyatakan dengan matriks $F=J(F)$ dan $\mathrm{V}=\mathrm{J}(\mathrm{V})$, sehingga diproleh

- $J(F)=\left[\begin{array}{cc}\rho S & 0 \\ \delta & 0\end{array}\right]$

- $J(V)=\left[\begin{array}{cc}\rho+\lambda+\delta & 0 \\ \delta & \rho\end{array}\right]$ 
Selanjutnya dengan subtitusi titik tetap bebas penyakit pada $\mathrm{J}(\mathrm{F})$ dan $\mathrm{J}(\mathrm{V})$

- $J(F)=\left[\begin{array}{cc}\rho S & 0 \\ \delta & 0\end{array}\right]$

$$
F=\left[\begin{array}{cc}
\rho\left(\frac{(1-\alpha) \mu}{[\alpha+\rho+(1-\alpha)]}\right) & 0 \\
\delta & 0
\end{array}\right]
$$

- $J(V)=\left[\begin{array}{cc}\rho+\lambda+\delta & 0 \\ \delta & \rho\end{array}\right]$

$$
V=\left[\begin{array}{cc}
\rho+\lambda+\delta & 0 \\
\delta & \rho
\end{array}\right]
$$

Selanjutnya kita dapatkan matriks next generation (K)

$$
\begin{aligned}
& V^{-1}=\frac{1}{\operatorname{Det} V} x \text { Adjoin matriks } V \\
& =\frac{1}{(\rho-\lambda+\delta) \rho} x\left[\begin{array}{cc}
\rho & 0 \\
0 & \rho+\lambda+\delta
\end{array}\right] \\
& =\left[\begin{array}{cc}
\frac{1}{\rho+\lambda+\delta} & 0 \\
0 & \frac{1}{\rho}
\end{array}\right] \\
& K=F x V^{-1} \\
& K=\left[\begin{array}{cc}
\rho\left(\frac{(1-\alpha) \mu}{[\alpha+\rho+(1-\alpha)] \rho}\right) & 0 \\
\delta & 0
\end{array}\right]\left[\begin{array}{cc}
\frac{1}{\rho+\lambda+\delta} & 0 \\
0 & \frac{1}{\rho}
\end{array}\right] \\
& =\left[\begin{array}{cc}
\frac{\rho[(1-\alpha) \mu}{[\alpha+\rho+(1-\alpha) \rho] \cdot[\rho+\lambda+\delta]} & 0 \\
\frac{\delta}{\rho+\lambda+\delta} & 0
\end{array}\right]
\end{aligned}
$$

Untuk menentukan nilai eigen dari matriks $K$, dituliskan bentuk persamaan karakteristik dari matriks K, yaitu

$$
\begin{gathered}
|K-\lambda I|=\|\left[\begin{array}{cc}
\frac{\rho[(1-\alpha)]}{[\alpha+\rho+(1-\alpha) \rho] \cdot[\rho+\lambda+\delta]} & 0 \\
\frac{\delta}{\rho+\lambda+\delta} & 0
\end{array}\right]-\left[\begin{array}{cc}
\lambda & 0 \\
0 & \lambda
\end{array}\right] \\
=\|\left[\begin{array}{cc}
\frac{\rho[(1-\alpha) \mu]}{[\alpha+\rho+(1-\alpha) \rho] \cdot[\rho+\lambda+\delta]}-\lambda & 0 \\
\frac{\delta}{\rho+\lambda+\delta} & -\lambda
\end{array}\right]
\end{gathered}
$$

Misalkan: 
- $\frac{\rho[(1-\alpha) \mu]}{[\alpha+\rho+(1-\alpha) \rho] \cdot[\rho+\lambda+\delta]}=k_{1}$

- $\frac{\delta}{\rho+\lambda+\delta}=k_{2}$

Sehingga $|k-\lambda I|=0$

$$
\begin{aligned}
\left|\begin{array}{cc}
k_{1}-\lambda & 0 \\
k_{2} & -\lambda
\end{array}\right|=0 \\
\left(k_{1}-\lambda\right)(-\lambda)-0=0 \\
-k_{1} \lambda+\lambda^{2}=0 \\
\left(-k_{1}+\lambda\right) \lambda=0 \\
\lambda_{1}=0 \\
k_{1}+\lambda=0 \\
\lambda_{2}=k_{1}
\end{aligned}
$$

Karena $R_{0}$ nilai eigen dominan, maka $R_{0}=k_{1}$

$$
R_{0}=\frac{\rho[(1-\alpha) \mu]}{[\alpha+\rho+(1-\alpha) \rho] \cdot[\rho+\lambda+\delta]}
$$

$\mathrm{R}_{0}$ merupakan nilai ambang batas epidemik yang akan menjadi tolak ukur tingkat penyebaran Tuberkulosis dalam populasi. Kondisi yang memungkinkan dari bilangan reproduksi menurut van den Driessche \& Watmough [8] adalah:

1) Jika $R 0<1$, maka jumlah individu yang terinfeksi akan menurun pada setiap generasi, sehingga penyakit akan menghilang.

2) Jika R0 $>$ 1, maka jumlah individu yang terinfeksi akan meningkat pada setiap generasi, sehingga penyakit akan meningkat dan mewabah.

\subsubsection{Mencari Matriks Jacobi}

$$
J=\left[\begin{array}{cccc}
-[\alpha+\rho+(1-\alpha)] & 0 & 0 & 0 \\
1-\alpha & -\rho-\beta I & -\beta S & 0 \\
0 & \beta I & \beta S-\rho-\lambda-\delta & 0 \\
-\alpha & 0 & 0 & \delta
\end{array}\right]
$$

Misalkan:

$$
\begin{aligned}
& a=-[\alpha+\rho+(1-\alpha)] \\
& b=1-\alpha \\
& c=-\rho-\beta I \\
& d=-\beta S \\
& e=\beta I \\
& f=\beta S-\rho-\lambda-\delta \\
& g=\alpha
\end{aligned}
$$




$$
\begin{aligned}
& h=\delta \\
& I=-\rho
\end{aligned}
$$

Sehingga :

$$
\begin{aligned}
& J=\left[\begin{array}{llll}
a & 0 & 0 & 0 \\
b & c & d & 0 \\
0 & e & f & 0 \\
g & 0 & h & i
\end{array}\right] \text { kalikan dengan }-\frac{d}{f} \cdot b_{3}+b_{2} \\
& J=\left[\begin{array}{cccc}
a & 0 & 0 & 0 \\
b & -\frac{d e}{f} & 0 & 0 \\
0 & e & f & 0 \\
g & 0 & h & i
\end{array}\right] \\
& |J|=(a) \cdot\left(-\frac{d e}{f}+c\right) \cdot(f) \cdot(i) \\
& =(a) \cdot\left(\frac{c f-d e}{f}\right) \cdot(f) \cdot(i) \\
& =(a) \cdot(c f-d e) \cdot(i) \\
& |J-\lambda I|=0 \\
& (a-\lambda) \cdot[(c-\lambda)(f-\lambda)-d e] .(1-\lambda)=0 \\
& \text { - } a-\lambda=0 \\
& -\lambda=-a \\
& \lambda=a \\
& \lambda_{1}=-[\alpha+\rho+(1-\alpha)] \\
& \text { - } 1-\lambda=0 \\
& -\lambda=-i \\
& \lambda=i \\
& \lambda_{2}=-\rho
\end{aligned}
$$

Dengan menggunakan rumus A B C kita dapatkan $\lambda_{3}$ dan $\lambda_{4}$ yaitu:

Misalkan $a=1, b=-(c+f), c=c f+d e$, maka:

$$
\begin{aligned}
& \lambda_{3,4}=\frac{-b \pm \sqrt{b^{2}-4 a c}}{2 a} \\
& \lambda_{3,4}=\frac{-(-(c+f)) \pm \sqrt{(-(c+f))^{2}-4(1)(c f-d e)}}{2(1)}
\end{aligned}
$$




$$
\begin{aligned}
\lambda_{3,4} & =\frac{(c+f) \pm \sqrt{\left.c^{2}+f^{2}+2 c f-4 c f+4 d e\right)}}{2} \\
\lambda_{3} & =\frac{\left.(c+f)+\sqrt{c^{2}+f^{2}+2 c f-4 c f+4 d e}\right)}{2} \\
\lambda_{4} & =\frac{\left.(c+f)-\sqrt{c^{2}+f^{2}+2 c f-4 c f+4 d e}\right)}{2}
\end{aligned}
$$

Dengan menggunakan Aplikasi Wolfram Mathematica 11.3 maka diperoleh nilai Eigen yaitu :

$$
\left\{\begin{array}{c}
-\rho,-1-\rho,-\frac{\beta(\mu-\alpha \mu)+\sqrt{(-1+\alpha)^{2} \beta^{2} \mu^{2}+4(-1+\alpha) \beta \mu(1+\rho)(\delta+\lambda+\rho)^{2}+4 \rho(1+\rho)^{2}(\delta+\lambda+\rho)^{3}}}{2(1+\rho)(\delta+\lambda+\rho)}, \\
\frac{(1-\alpha) \beta \mu+\sqrt{(-1+\alpha)^{2} \beta^{2} \mu^{2}+4(-1+\alpha) \beta \mu(1+\rho)(\delta+\lambda+\rho)^{2}+4 \rho(1+\rho)^{2}(\delta+\lambda+\rho)^{3}}}{2(1+\rho)(\delta+\lambda+\rho)}
\end{array}\right\}
$$

$\lambda_{1}=-\rho$

$\lambda_{2}=-1-\rho$

$\lambda_{3}$

$=-\frac{\beta(\mu-\alpha \mu)+\sqrt{(-1+\alpha)^{2} \beta^{2} \mu^{2}+4(-1+\alpha) \beta \mu(1+\rho)(\delta+\lambda+\rho)^{2}+4 \rho(1+\rho)^{2}(\delta+\lambda+\rho)^{3}}}{2(1+\rho)(\delta+\lambda+\rho)}$

$\lambda_{4}$

$=\frac{(-1+\alpha) \beta \mu+\sqrt{(-1+\alpha)^{2} \beta^{2} \mu^{2}+4(-1+\alpha) \beta \mu(1+\rho)(\delta+\lambda+\rho)^{2}+4 \rho(1+\rho)^{2}(\delta+\lambda+\rho)^{3}}}{2(1+\rho)(\delta+\lambda+\rho)}$

\subsubsection{Simulasi Numerik}

Tahun 2014, profil kesehatan 2015 di Yogyakarta ada penemuan kasus penderita TBC sebanyak 491 jiwa. Jumlah penduduk Yogyakarta saat itu sebanyak 413.936 jiwa, 202.296 penduduk laki-laki dan 211.640 penduduk perempuan dengan banyaknya kelahiran sebesar 0.0879578900321 Banyaknya kematian disebabkan penyakit TBC 10 orang dalam 1 tahun [5], sehingga

$$
\lambda=\frac{10}{491 \times 12}=\frac{5}{2946}
$$

Maka diasumsikan rata-rata usia hidup manusia adalah 70, maka diperoleh

$$
\rho=\frac{10}{491 \times 12}
$$

Dengan tingkat keberhasilan Vaksin adalah 0.73. laju individu terinfeksi adalah 0,0015 dan laju individu sembuh adalah 0,027. Populasi bayi (B) 100, populasi Rentan (S) 600, populasi Infeksi (I) 20, populasi Sembuh (R) 0. Berdasarkan nilai-nilai parameter dan 
variabel diperoleh $R_{0}<1$ Dinamika penyebaran penyakit Tuberkulosis dengan vaksinasi diperoleh dalam Gambar 2.

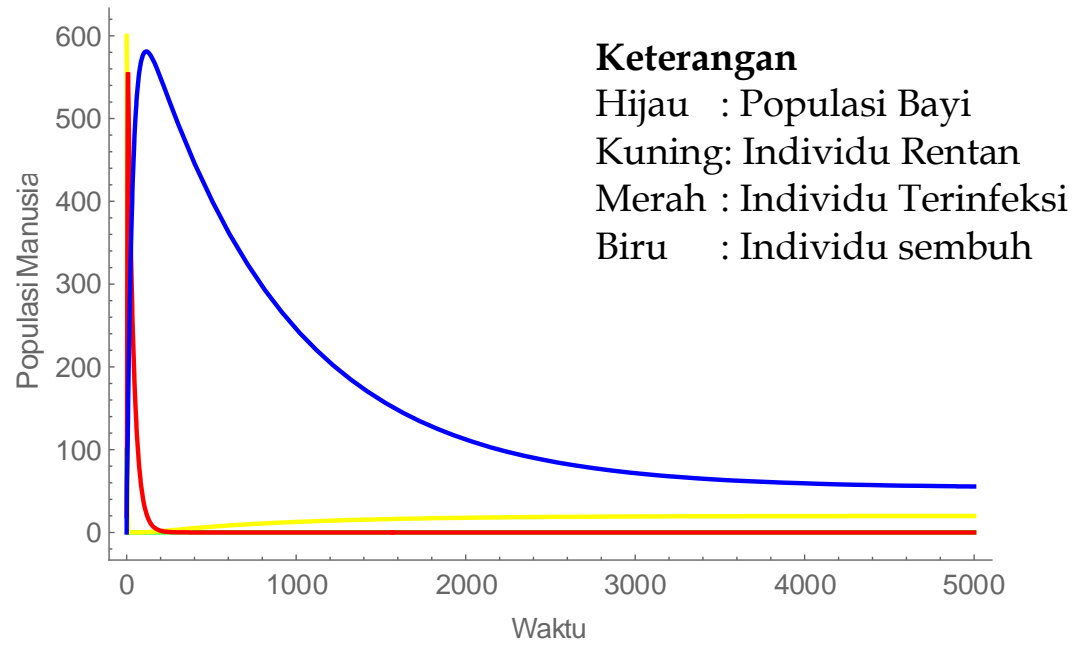

Gambar 2. Dinamika populasi pada kondisi $R_{0}<1$

Berdasarkan grafik yang diperoleh maka dapat dilihat bahwa populasi bayi yang nanntinya akan menuju rentan itu terlihat langsung turun dari 100 menjadi 0 di hari pertama pada saat langsung diberikan vaksin. Populasi Rentan mengalami penurunan dari 600 sampai pada 0 individu kemudian naik kembali dan stabil pada titik 20 di hari yang ke-2000. Untuk populasi terinfeksi naik dari titik 20 ke titik 550 pada hari ke 20 dan turun terus sampai stabil pada titik 0 di hari yang ke-200. Dan untuk indifidu sembuh mengalami kenaikan dari titik 0 sampai pada 600 di hari ke-100 dan mengalami penurunan terus menerus sampai stabil pada titik 80 di hari ke-5000.

\section{Kesimpulan}

Berdasarkan pembahasan yang telah di uraikan di atas dapat disimpilkan bahwa populasi yang terinfeksi seiring berjalannya waktu akan hilang dari populasi, kemudian populasi yang rentan seiring berjalannya waktu akan mengalami penurunan karena adanya vaksinasi yang diberikan pada bayi sejak lahir, dimana untuk populasi bayi sendiri langsung kebal terhadap penyakit dan tidak akan mungkin lagi menjadi populasi rentan. Populasi yang sembuh seiring berjalannya waktu akan stabil di jumlah 80 orang di hari yang ke 5000 .

\section{Referensi}

[1] N. F. Setiawan, "Analisis dan Simulasi Model SITR pada Penyebaran Penyakit Tuberkulosis di Kota Makassar," Universitas Negeri Makassar, Makassar, 2017.

[2] K. Q. Fredlina, T. B. Oka, and I. M. E. Dwipayana, " Model SIR (Susceptible, Infected, Recovered) untuk Penyebaran Penyakit Tuberkulosis," E-Jurnal Matematika ., vol. 1, no. 1, pp. 52-58, Aug. 2012.

[Online].

Available: 
https://id.m.wikipedia.org/wiki/Vaksinasi. [Accessed: 11-Des-2019].

[4] M. Soleh, and S. Rahma, "Model SEIR Penyakit Campak dengan Vaksinasi dan Migrasi," Jurnal Sains, Teknolodi dan Industri., vol. 9, no. 2, pp. 113-123, 2012.

[5] O. Rositarini, D. Lestari, and H. Arifah "Analisis Numerik Model Epidemik SIR (Susceptible, Infected, Recovered) Pada Penyebaran Penyakit Tuberculosis di Yogyakarta," Seminar Matematika dan Pendidikan Matematika UNY., pp. 171-178, 2017

[6] N. T. Pambudi and D. Lestari, " Analisis Sensitivitas Model SIR (Susceptible, Infected, Recovered) pada Penyebaran Penyakit Tuberkulosis di Yogyakarta," Jurnal Matematika - S1., vol. 7, no. 2, pp. 1-13, 2018.

[7] K. A. Setiaputri, "Informasi Penting Soal Vaksin TBC yang Wajib Anda Ketahui,” 2018. [Online]. Available: https://hellosehat.com/pusat-kesehatan/batukpenyakit-pernapasan/informasi-vaksin-tbc-vaksin-bcg/. [Accessed: 18-Des2019].

[8] P. van den Driessche and J. Watmough, "Reproduction numbers and subthreshold endemic equilibria for compartmental models of disease transmission" in Mathematical Biosciences, 2002.

[9] R. Resmawan and N. Nurwan, "Konstruksi Bilangan Reproduksi Dasar pada Model Epidemik SEIRS-SEI Penyebaran Malaria dengan Vaksinasi dan Pengobatan," J. Mat. Integr., vol. 13, no. 2, p. 105, Sep. 2017.

[10] R. Resmawan and L. Yahya, "Sensitivity Analysis of Mathematical Model of Coronavirus Disease (COVID-19) Transmission," CAUCHY, vol. 6, no. 2, pp. 9199, May 2020. 